\title{
Inhibition of MEK1 Signaling Pathway in the Liver Ameliorates Insulin Resistance
}

\author{
Atsunori Ueyama, ${ }^{1,2}$ Nobuhiro Ban, ${ }^{1}$ Masanori Fukazawa, ${ }^{1}$ Tohru Hirayama, \\ Minako Takeda, ${ }^{1}$ Tatsuo Yata, ${ }^{3}$ Hiroyasu Muramatsu, ${ }^{1}$ Masaki Hoshino, ${ }^{1}$ \\ Marii Yamamoto, ${ }^{1}$ Masao Matsuo, ${ }^{1}$ Yuka Kawashima, ${ }^{1}$ Tatsuhiko Iwase, ${ }^{4}$ \\ Takehisa Kitazawa, ${ }^{1}$ Youichi Kushima, ${ }^{1}$ Yuichiro Yamada, ${ }^{2}$ and Yoshiki Kawabe ${ }^{1}$ \\ ${ }^{1}$ Research Division, Chugai Pharmaceutical Co., Ltd., 1-135 Komakado, Gotemba, Shizuoka 412-8513, Japan \\ ${ }^{2}$ Department of Endocrinology, Diabetes and Geriatric Medicine, Akita University School of Medicine, 1-1-1 Hondo, Akita, \\ Akita 010-8543, Japan \\ ${ }^{3}$ Chugai Research Institute for Medical Science, 1-135 Komakado, Gotemba, Shizuoka 412-8513, Japan \\ ${ }^{4}$ Project Planning \& Coordination Department, Chugai Pharmaceutical Co., Ltd., 2-1-1 Nihonbashi, Muromachi, \\ Chuo-ku, Tokyo 103-8324, Japan
}

Correspondence should be addressed to Atsunori Ueyama; ueyamaatn@chugai-pharm.co.jp

Received 16 June 2015; Revised 26 September 2015; Accepted 29 September 2015

Academic Editor: Raffaella Mastrocola

Copyright (C 2016 Atsunori Ueyama et al. This is an open access article distributed under the Creative Commons Attribution License, which permits unrestricted use, distribution, and reproduction in any medium, provided the original work is properly cited.

\begin{abstract}
Although mitogen-activated protein kinase kinase (MEK) is a key signaling molecule and a negative regulator of insulin action, it is still uncertain whether MEK can be a therapeutic target for amelioration of insulin resistance (IR) in type 2 diabetes (T2D) in vivo. To clarify whether MEK inhibition improves T2D, we examined the effect of continuous MEK inhibition with two structurally different MEK inhibitors, RO5126766 and RO4987655, in mouse models of T2D. RO5126766 and RO4987655 were administered via dietary admixture. Both compounds decreased blood glucose and improved glucose tolerance in doses sufficient to sustain inhibition of extracellular signal-regulated kinase (ERK)1/2 phosphorylation downstream of MEK in insulin-responsive tissues in $d b / d b$ mice. A hyperinsulinemic-euglycemic clamp test showed increased glucose infusion rate (GIR) in $d b / d b$ mice treated with these compounds, and about $60 \%$ of the increase was attributed to the inhibition of endogenous glucose production, suggesting that the liver is responsible for the improvement of IR. By means of adenovirus-mediated Mekl shRNA expression, we confirmed that blood glucose levels are reduced by suppression of MEK1 expression in the liver of $d b / d b$ mice. Taken together, these results suggested that the MEK signaling pathway could be a novel therapeutic target for novel antidiabetic agents.
\end{abstract}

\section{Introduction}

The pathology of type 2 diabetes (T2D) is characterized by impaired insulin secretion from pancreatic beta cells and impaired insulin action, known as insulin resistance (IR). Although glucagon-like peptide-1 receptor agonists and sodium-glucose cotransporter 2 inhibitors $[1,2]$ have become available to treat $\mathrm{T} 2 \mathrm{D}$, currently the only clinically available insulin sensitizers are peroxisome proliferator-activated receptor (PPAR) $\gamma$ agonists, such as pioglitazone.
Insulin initiates the regulation of various cell functions through the phosphoinositide 3-kinase (PI 3-K) pathway and the mitogen-activated protein kinase kinase (MEK) pathway after binding to insulin receptors and becoming phosphorylated $[3,4]$. It is believed that the PI 3 -K pathway is important in glucose metabolism [5], whereas the MEK pathway is considered to mainly control cell growth and differentiation $[6,7]$; however, the precise role of MEK in the regulation of glucose metabolism by insulin is still not fully established. There are several lines of in vitro evidence suggesting that 


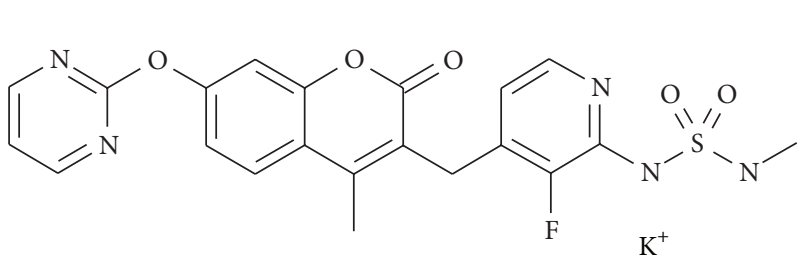

(a)

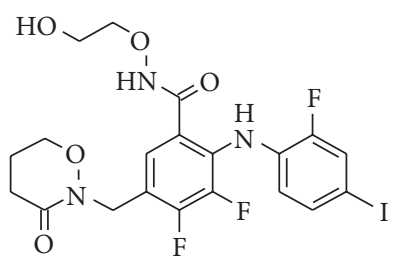

(b)

FIGURE 1: Chemical structures of (a) RO5126766 (dual Raf/MEK inhibitor) and (b) RO4987655 (specific MEK1/2 inhibitor).

the MEK pathway negatively regulates insulin action: (i) activated extracellular signal-regulated kinase (ERK) phosphorylates IRS-1 $\mathrm{Ser}^{307}$ residue and impairs insulin signal transduction [5, 8-11]; (ii) MEK inhibition leads to increased protein kinase B (Akt) phosphorylation and to improved insulin signaling accompanied by the reduction in IRS-1 $\mathrm{Ser}^{307}$ phosphorylation [12]; and (iii) MEK1 is a major kinase involved in inducing IR in 3T3-L1 adipocytes [11]. On the other hand, it has been reported that the constitutive active form of MEK expressed in the liver has insulinotropic effects without altering insulin sensitivity in vivo [13]. From gene knockout studies in mice, it has been reported that ERK1 knockout mice are fertile and of normal size and have defective $\mathrm{T}$ cell differentiation, enhanced long-term memory, and potentiation in the nucleus accumbens, decreased adiposity, and improved insulin sensitivity [14-17]. On the other hand, MEK1 or ERK2 knockout mice are embryonic lethal [1821]. Therefore, it is unclear whether MEK is an appropriate therapeutic target for ameliorating insulin resistance in T2D.

Two novel MEK inhibitors (RO4987655 and RO5126766) are currently under clinical development for cancer treatment. A Phase 1 dose escalation study of RO4987655, a pure MEK inhibitor, has been completed [22] and an expansion study is ongoing [23]. Phase 1 studies of RO5126766, a dual Raf/MEK inhibitor [24, 25], have been completed in both Japan and Europe [26, 27], and an alternative study is ongoing.

In the present study, we describe the antidiabetic effect of MEK inhibition with these MEK inhibitors in $d b / d b$ mice, a T2D animal model, and explore the mechanism underlying the glucose lowering effect of MEK1 inhibition.

\section{Materials and Methods}

2.1. Materials. RO5126766 (3-[[3-fluoro-2-(methylsulfamoylamino)-4-pyridyl]methyl]-4-methyl-7-pyrimidin-2-yloxychromen-2-one) (Figure 1(a)) [24-26] and RO4987655 (3,4-difluoro-2-((2-fluoro-4-iodophenyl)amino)-N-(2-hydroxyethoxy)-5-((3-oxo-1,2-oxazinan-2-yl)methyl)benzamide) (Figure 1(b)) [22, 28] were synthesized in our laboratories at Chugai Pharmaceutical Co., Ltd. Pioglitazone hydrochloride was purchased from Tokyo Chemical Industry Co., Ltd. (Tokyo, Japan). Insulin (Novolin R; $100 \mathrm{IU} \cdot \mathrm{mL}^{-1}$ ) was purchased from Novo Nordisk Pharma (Tokyo, Japan). Uniformly labeled $\left[\mathrm{U}_{-}{ }^{13} \mathrm{C}\right]$ glucose (99-atom percent excess) was purchased from Cambridge Isotope Laboratories (Andover, MA, USA). Glucose solution (50\%) was purchased from Otsuka Pharmaceutical Factory Inc. (Tokushima, Japan). Glucose solution (50\%) was diluted with purified water to make concentrations of $20 \%$ for the oral glucose tolerance test (OGTT) and $10 \%$ for the hyperinsulinemic-euglycemic clamp test. Insulin ELISA kit was purchased from Morinaga Institute of Biological Science, Inc. (Yokohama, Japan). RIPA buffer, Halt protease inhibitor cocktail (100x), Halt phosphatase inhibitor cocktail (100x), and SuperSignal West Femto Maximum Sensitivity Substrate were purchased from Thermo Fisher Scientific (Rockford, IL, USA). Polyvinylidene difluoride membrane (PVDF) $(0.2 \mu \mathrm{m})$ was purchased from Bio-Rad Laboratories Inc. (Hercules, CA, USA).

2.2. Preparation of Dietary Admixtures. High-concentration stock solutions of RO5126766 or RO4987655 were made by dissolving the compound in water or ethanol, respectively. After dilution to $3.44 \mathrm{mg} \cdot 50 \mathrm{~mL}^{-1}$ (RO5126766) and $8 \mathrm{mg} \cdot 50 \mathrm{~mL}^{-1}$ (RO4987655) with the same vehicle, they were added little by little to $1 \mathrm{~kg}$ of laboratory chow (CE-2 powder; CLEA Japan, Tokyo, Japan) and mixed using a food processor. The mixtures were then dried with a vacuum pump for at least overnight to remove the vehicle. Dietary admixtures comprising several different dosages of RO5126766 or RO4987655 were made in this way and stored at $-30^{\circ} \mathrm{C}$ until use.

2.3. Animals. All animal care and experiments were performed in accordance with the guidelines for the care and use of laboratory animals at Chugai Pharmaceutical Co., Ltd., and all protocols were approved by the Institutional Animal Care and Use Committee at Chugai Pharmaceutical Co., Ltd. Seven-week-old male $d b / d b$ mice (BKS.Cg$\left.+\operatorname{Lepr}^{d b} /+\operatorname{Lepr}^{d b} / \mathrm{Jcl}\right)$ were purchased from CLEA Japan. These animals were housed under a $12 \mathrm{~h}: 12 \mathrm{~h}$ light/dark cycle (lights on 7:00 a.m.-7:00 p.m.) with controlled room temperature $\left(20^{\circ} \mathrm{C}-26^{\circ} \mathrm{C}\right)$ and humidity $(35 \%-75 \%)$ and were allowed ad libitum access to a diet of CE- 2 powder and water. RO5126766 and RO4987655 were administered as a dietary admixture with CE-2.

2.4. Animal Experiments. Mice were randomly divided into groups based on body weight (BW) and blood glucose levels by SAS System for Windows, Release 8.02 (SAS Institute Japan, Tokyo, Japan).

For the pharmacological evaluation of RO5126766 and RO4987655, we performed two separate experiments with 
mice divided into the following groups ( $n=$ number of animals). In the RO5126766 experiment, each group received $0 \mathrm{mg}$ in $1 \mathrm{~kg} \mathrm{CE}-2(n=6), 0.86 \mathrm{mg}$ in $1 \mathrm{~kg} \mathrm{CE}-2(n=5)$, $1.72 \mathrm{mg}$ in $1 \mathrm{~kg} \mathrm{CE}-2(n=5)$, or $3.44 \mathrm{mg}$ in $1 \mathrm{~kg} \mathrm{CE}-2(n=5)$. In the RO4987655 experiment, each group received $0 \mathrm{mg}$ in $1 \mathrm{~kg} \mathrm{CE}-2(n=6), 2 \mathrm{mg}$ in $1 \mathrm{~kg} \mathrm{CE}-2(n=6), 4 \mathrm{mg}$ in $1 \mathrm{~kg} \mathrm{CE}-2$ $(n=6)$, or $8 \mathrm{mg}$ in $1 \mathrm{~kg} \mathrm{CE}-2(n=6)$. During the treatment period, food intake (FI) and BW were measured. After 14 days of treatment with the compounds, animals underwent OGTT and then compound admixtures were given for another 3 days. Thereafter, under anesthesia with isoflurane, blood samples were taken and animals were killed, and insulinresponsive tissues were harvested for western blotting.

For the analysis of the mode of action of these compounds, hyperinsulinemic clamp tests were performed after treatment with each of the compounds for 9-11 days in two separate experiments. Mice were divided into the following groups ( $n=$ number of animals): control $(n=10)$, RO5126766 $(2 \mathrm{mg}$ in $1 \mathrm{~kg} \mathrm{CE}-2, n=10)$, and pioglitazone $(200 \mathrm{mg}$ in $1 \mathrm{~kg}$ $\mathrm{CE}-2, n=5)$; and control $(n=10), \mathrm{RO} 4987655(8 \mathrm{mg}$ in $1 \mathrm{~kg}$ $\mathrm{CE}-2, n=9)$, and pioglitazone (200 $\mathrm{mg}$ in $1 \mathrm{~kg} \mathrm{CE}-2, n=10)$.

For the evaluation of the effect of MEK1 knockdown, we administered shRNA of Mek1 intravenously to $d b / d b$ mice; after 3 days, blood glucose, BW, and FI were measured, the animals were killed under anesthesia with isoflurane, and then the liver was taken for western blotting and qRT-PCR.

2.5. Oral Glucose Tolerance Test (OGTT). After administration of RO5126766 and RO4987655 as a dietary admixture for 14 days, mice were fasted overnight. Next morning, blood glucose was measured at 30,60,120, and $240 \mathrm{~min}$ after oral administration of glucose $\left(2 \mathrm{~g} \cdot \mathrm{kg}^{-1}\right.$ of $20 \%$ glucose solution) using Accu-Chek Aviva (Roche Diagnostics, Tokyo, Japan).

2.6. Hyperinsulinemic-Euglycemic Clamp Test. The hyperinsulinemic-euglycemic clamp test was performed as previously described [1] with slight modifications. RO5126766 and RO4987655 were administered as a dietary admixture to $d b / d b$ mice as described above. On day 7 or 8 , two jugular vein cannulae were inserted under anesthesia (sodium pentobarbital, $60 \mathrm{mg} \cdot \mathrm{kg}^{-1}$, additional as appropriate) and analgesia (bupivacaine hydrochloride, $0.5 \%$ ) and then passed subcutaneously to the back. Then the cannulae were connected to swivels through a tether, and the swivels were fixed to a metal rack. Heparin solution $\left(50 \mathrm{U} \cdot \mathrm{mL}^{-1}\right.$ at the rate of $12 \mu \mathrm{L} \cdot \mathrm{h}^{-1}$ ) was continuously infused with a daily flush $\left(50 \mu \mathrm{L} \cdot \mathrm{head}^{-1}\right)$ until the day of the clamp test. After a 2- to 4-day recovery period with continuing feeding of the dietary admixture, on day 10 or 11, the hyperinsulinemic-euglycemic clamp test was conducted. In the morning, diet was removed and $\left[\mathrm{U}^{-13} \mathrm{C}\right.$ ] glucose infusion $\left(0.5 \mathrm{mg} \cdot \mathrm{kg}^{-1} \cdot \mathrm{min}^{-1}\right)$ was started. After $2 \mathrm{~h}$, blood was collected for the measurement of basal endogenous glucose production (EGP); thereafter, insulin $\left(25 \mathrm{IU} \cdot \mathrm{kg}^{-1} \cdot \mathrm{min}^{-1}\right)$ infusion was started. Blood glucose level was monitored by Accu-Chek Aviva at $10 \mathrm{~min}$ intervals. When blood glucose reached nearly $110 \mathrm{mg} \cdot \mathrm{dL}^{-1}$, glucose $(10 \%)$ infusion was initiated to maintain blood glucose at $110 \mathrm{mg} \cdot \mathrm{dL}^{-1}$. Glucose infusion rate (GIR) was calculated from the following calculation formula, which is a slightly modified version of a previously described formula [29],

$$
\begin{aligned}
I_{2}= & I_{1} \frac{T_{s}-T_{d}}{T_{s}}+I_{0} \frac{T_{d}}{T_{s}}+\frac{V(\mathrm{GD}-\mathrm{GM})}{k_{p} T_{s}} \\
& +\frac{V(\mathrm{GP}-\mathrm{GM})}{k_{d} T_{s}},
\end{aligned}
$$

where $I_{2}, I_{1}$, and $I_{0}$ are the GIR $\left(\mathrm{mg} \cdot \mathrm{kg}^{-1} \cdot \mathrm{min}^{-1}\right), T_{s}$ is the sampling interval $(=10 \mathrm{~min}), T_{d}$ is the delay time taken to adjust the glucose infusion pump after measuring blood glucose $(=2 \mathrm{~min})$, GD is the target blood glucose level (= $\left.110 \mathrm{mg} \cdot \mathrm{dL}^{-1}\right), \mathrm{GM}$ is the current blood glucose level, GP is the blood glucose just $10 \mathrm{~min}$ before, $V$ is the initial volume of distribution of glucose in $d b / d b$ mice ( $=16 \%$ of BW), and $k_{p}$ and $k_{d}$ are correction coefficients (1 or 2).

When GIR and blood glucose reached a steady state, the mean GIR for the previous $60 \mathrm{~min}$ (150-210 min in most cases) was calculated and blood was collected to measure the clamp state EGP and insulin level. All mice were euthanized by exsanguination under anesthesia (sodium pentobarbital, $60 \mathrm{mg} \cdot \mathrm{kg}^{-1}$, additional as appropriate) and analgesia (bupivacaine hydrochloride, $0.5 \%$ ) at the end of the clamp period. Plasma insulin was measured by insulin ELISA kit according to the instruction manual. Plasma $\left[\mathrm{U}_{-}{ }^{13} \mathrm{C}\right]$ glucose concentrations, together with that of an internal standard (fructose), were determined with an HPLC-MS/MS system (Shimadzu 20A, Shimadzu, Kyoto, Japan; API 4000, AB Sciex, Framingham, MA, USA) with an improved procedure to increase the sensitivity by $\mathrm{Cs}^{+}$attachment to the sugars $[1,30]$. The rate of EGP was calculated according to the following equation, as previously described $[1,31]$ :

$$
\mathrm{EGP}=f\left(\frac{\mathrm{IE}_{\text {infusate }}}{\mathrm{IE}_{\text {plasma }}}-1\right),
$$

where EGP is the rate of endogenous glucose production, $f$ is the infusion rate of $\left[\mathrm{U}_{-}{ }^{13} \mathrm{C}\right]$ glucose $\left(0.5 \mathrm{mg} \cdot \mathrm{kg}^{-1} \cdot \mathrm{min}^{-1}\right)$, $\mathrm{IE}_{\text {infusate }}$ is the isotopic enrichment of $\left[\mathrm{U}_{-}{ }^{13} \mathrm{C}\right]$ glucose in infusate, and $\mathrm{IE}_{\text {plasma }}$ is the isotopic enrichment (\%) of [U${ }^{13} \mathrm{C}$ ]glucose in plasma (= plasma $\left[\mathrm{U}_{-}{ }^{13} \mathrm{C}\right]$ glucose concentration/total plasma glucose concentration $\times 100$ ).

2.7. Adenovirus-Mediated shRNA Mek1 Treatment. The adenovirus was prepared by the BLOCK-iT Adenoviral RNAi Expression System (Life Technology, Carlsbad, CA, USA) according to the instruction manual. The following sequences were used: shRNA Mek1 sequence Map2k1: 5'-GGCAGCTAATTGACTCTATGGCGAACCATAGAGTCAATTAGCTGCC-3', and scramble sequence: $5^{\prime}$-GGACTCGGGCCACCGGGTACGAATACCCGGTGGCCCGAGTCC- $3^{\prime}$.

A Fast-Trap Virus Purification/Concentration Kit (Millipore, Billerica, MA, USA) was used for purification and concentration of the adenovirus according to the instruction manual. Titer was determined using an Adeno-X Rapid Titer Kit (Clontech, Mountain View, CA, USA) according to 
the instruction manual, and infectious units (ifu) were calculated. The adenovirus was diluted to $5 \times 10^{10} \mathrm{ifu} \cdot 10 \mathrm{~mL}^{-1}$ with $20 \mathrm{mmol} \cdot \mathrm{L}^{-1}$ Tris- $\mathrm{HCl}, \mathrm{pH} 8.0$, containing $2 \%$ glycerol, and $200 \mathrm{mmol} \cdot \mathrm{L}^{-1} \mathrm{NaCl}$. The adenovirus was injected at a volume of $10 \mathrm{~mL} \cdot \mathrm{kg}^{-1}$ through the tail vein into $d b / d b$ mice fed a normal diet. Blood glucose, BW, and FI were measured 3 days after administration of the adenovirus under unanesthetized conditions. All mice were euthanized by exsanguination under anesthesia (isoflurane) at the end of the experimental period.

2.8. Antibodies. Phospho-p44/42 MAPK (ERK1/2) $\left(\mathrm{Thr}^{202} /\right.$ $\mathrm{Tyr}^{204}$, E10) antibody, p44/42 MAPK (ERK1/2) antibody, MEK1 antibody, MEK2 antibody, and horseradish peroxidase-conjugated secondary anti-rabbit and anti-mouse antibodies were purchased from Cell Signaling Technology (Beverly, MA, USA). Anti-tubulin alpha antibody, as a reference antibody, was purchased from Serotec (Oxford, UK). Horseradish peroxidase-conjugated secondary anti-rat antibody was purchased from Zymed (Carlsbad, CA, USA).

2.9. Western Blot Analysis. Western blot analysis was performed by the method previously reported [32, 33] with slight modifications. Tissue lysates were prepared using RIPA buffer in combination with protease inhibitors, phosphatase inhibitors, $1 \mathrm{mmol} \cdot \mathrm{L}^{-1} \mathrm{EDTA}$, and $2 \mathrm{mmol} \cdot \mathrm{L}^{-1}$ phenylmethylsulfonyl fluoride. After centrifugation $(20,000 \times \mathrm{g}$ for $10 \mathrm{~min}$, $4^{\circ} \mathrm{C}$ ), supernatant was collected and protein concentration was measured using bovine serum albumin as a standard. Aliquots of protein from the supernatant were dissolved in Laemmli sample buffer [34] containing $1 \mathrm{mmol} \cdot \mathrm{L}^{-1} \mathrm{DTT}$ and heated to $95^{\circ} \mathrm{C}$ for $5 \mathrm{~min}$. Equal amounts of protein from the sample buffer were loaded in each lane, resolved in SDS-PAGE, and transferred to PVDF membranes, which were incubated overnight at $4^{\circ} \mathrm{C}$ with specific primary antibodies. After incubation with horseradish peroxidaseconjugated secondary antibodies, membranes were incubated with chemiluminescent substrate and were detected using a Fujifilm LAS-4000 apparatus (Fujifilm Life Science, Tokyo, Japan). Some membranes were subsequently reprobed with the indicated antibody as a loading control. Quantifications were realized using MultiGauge software version 3.2.0.0 (Fujifilm Life Science).

2.10. Quantitative Real-Time Polymerase Chain Reaction ( $q R T-P C R)$. Tissue was lysed in RLT buffer (Qiagen, Limburg, Netherlands), and RNA was extracted from RLT buffer by using an RNeasy Mini kit (Qiagen) following the manufacturer's instructions. RNA yield and quality were determined by using a NanoDrop (NanoDrop Technologies, Wilmington, DE, USA). Real-time PCR reactions were performed with a 7900HT Fast Sequence Detection System (Life Technologies Japan, Tokyo, Japan). Relative mRNA levels were calculated with a delta-delta-Ct method normalized to $18 \mathrm{~S}$ rRNA levels as an internal control using the following primers: TaqMan Gene Expression Assay for Mouse Map2k1 (Applied Biosystems, Carlsbad, CA, USA; Assay ID: Mm00435940_ml) and Predeveloped TaqMan Assay Reagents 18S rRNA (20x) (Applied Biosystems, Catalog Number 4319413E).

2.11. Statistical Analysis. Data are expressed as mean \pm SEM. Statistical analysis was performed with SAS System for Windows, Release 8.02 (SAS Institute Japan). Statistical significance was determined by the parametric Dunnett's multiple comparison or Welch's test. $p$ values less than 0.05 were considered to be statistically significant.

\section{Results}

3.1. Effects of RO5126766 and RO4987655 on Blood Glucose in $d b / d b$ Mice. Three different doses of RO5126766 or RO4987655 were administrated as dietary admixtures to $\mathrm{db} / \mathrm{db}$ mice for 14 days. Mean dosages of RO5126766 and RO4987655 during the administration period were $0.14,0.27$, and $0.49 \mathrm{mg} \cdot \mathrm{kg}^{-1} \cdot \mathrm{day}^{-1}$ and $0.31,0.57$, and $1.25 \mathrm{mg} \cdot \mathrm{kg}^{-1} \cdot \mathrm{day}^{-1}$, respectively (data not shown). At the mid and high dosages, these compounds inhibited around $20 \%$ or more of pERK1/2 in peripheral blood mononuclear cells (PBMCs) at the end of the experimental period (Supplemental Figure S1 in Supplementary Material available online at http://dx.doi.org/10.1155/2016/8264830). Blood glucose decreased in a dose-dependent manner for both RO5126766 (Figure 2(c)) and RO4987655 (Figure 3(c)). During treatment with RO4987655, no effects on food intake (FI, Figure 3(a)) or BW gain (Figure 3(b)) were observed; however, during treatment with RO5126766, an approximately $30 \%$ reduction in mean FI was observed at the highest dose (Figure 2(a)) while there was no change in BW (Figure 2(b)).

After 14-day administration, mice were fasted overnight and OGTT was performed. The OGTT showed that, for both compounds, fasting blood glucose (FBG) decreased and glucose tolerance improved (Figures 2(d) and 3(d)) and the area under the curve (AUC) during OGTT was reduced (Figures 2(e) and 3(e)) in a dose-dependent manner.

Since mice treated with the highest dose of RO5126766 (3.44 mg in $1 \mathrm{~kg} \mathrm{CE-2)} \mathrm{showed} \mathrm{a} \mathrm{30 \%} \mathrm{reduction} \mathrm{in} \mathrm{FI}$ (Figure 2(a)), we used untreated age-matched $d b / d b$ mice to confirm that a $30 \%$ restriction of FI in itself did not lower the blood glucose level or AUC during OGTT to the same level as observed in RO5126766-treated mice (Figures 2(c)-2(e), Supplemental Figures S4(c)-S4(e)).

During the OGTT, plasma insulin levels in both RO5126766- and RO4987655-treated $d b / d b$ mice were comparable to that of control mice (Supplemental Figure S5). There were no obvious changes in laboratory test values in plasma from $d b / d b$ mice after 17 days of treatment with either compound (Supplemental Tables S2 and S3).

\subsection{Effects of RO5126766 and RO4987655 on pERK1/2 in} Insulin-Responsive Tissues from $d b / d b$ Mice. To make sure that the MEK inhibition occurred in insulin-responsive tissues as well as in PBMC, pERK1/2 was determined by western blotting in insulin-responsive tissues from $d b / d b$ mice to which RO5126766 (Figure 4) or RO4987655 (Figure 5) had been administered for 17 days. Phosphorylation of 


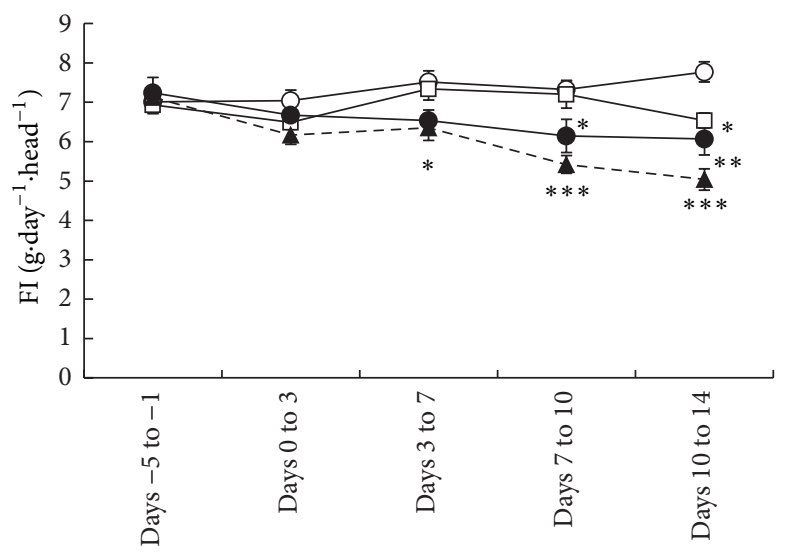

(a)

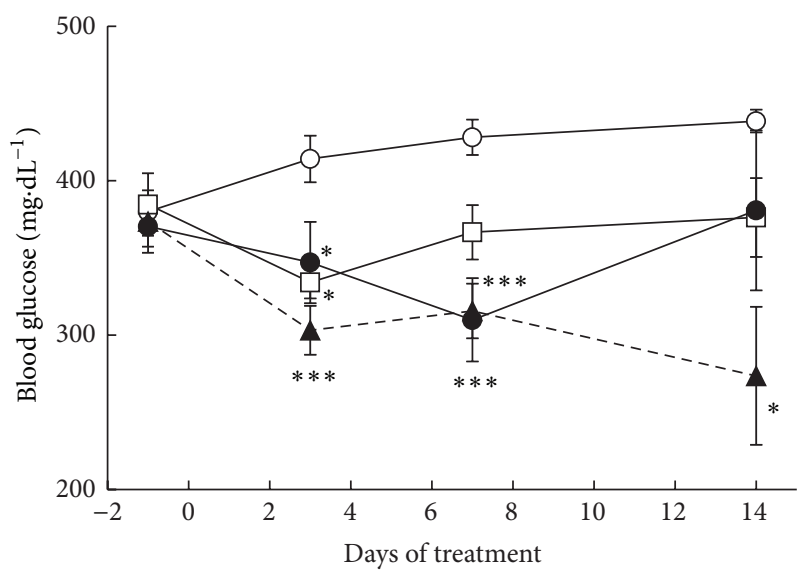

(c)

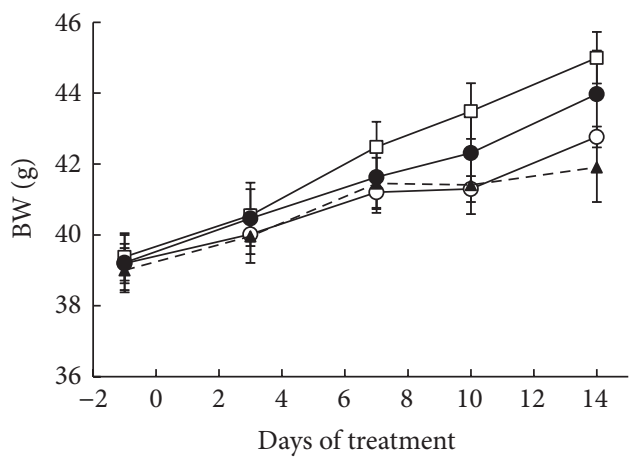

(b)

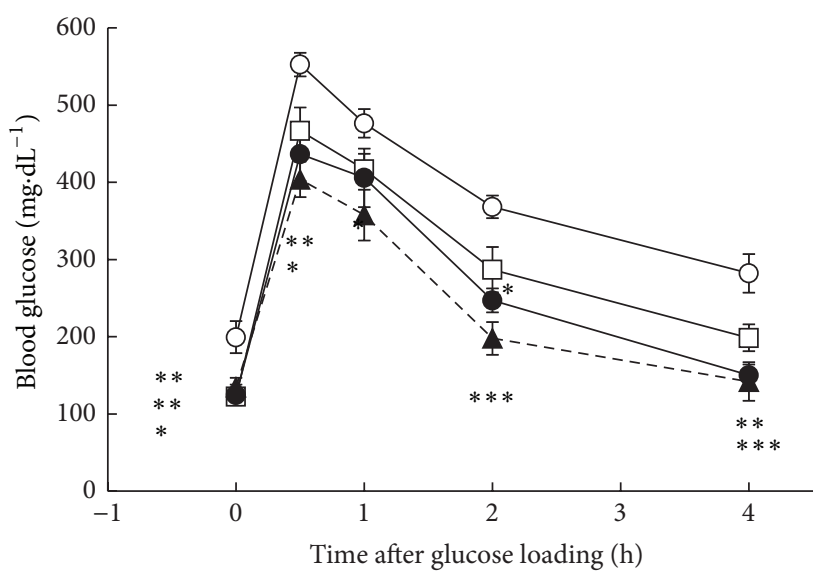

(d)

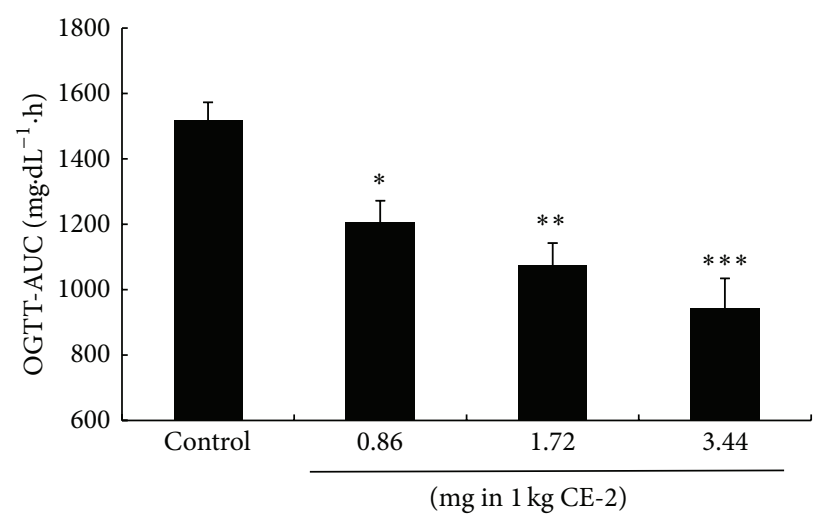

(e)

Figure 2: Effects of RO5126766 on (a) food intake (FI), (b) body weight (BW), (c) blood glucose, (d) glucose excursion, and (e) AUC during the oral glucose tolerance test (OGTT) in $d b / d b$ mice, with RO5126766 administered for 14 days as a dietary admixture with dosages as indicated: open circle, $0 \mathrm{mg}$ in $1 \mathrm{~kg} \mathrm{CE}-2$; open square, $0.86 \mathrm{mg}$ in $1 \mathrm{~kg}$ CE-2; closed circle, $1.72 \mathrm{mg}$ in $1 \mathrm{~kg}$ CE-2; and closed triangle, $3.44 \mathrm{mg}$ in $1 \mathrm{~kg} \mathrm{CE}-2$. Data are expressed as mean $\pm \mathrm{SEM}, n=6$ (control group, $0 \mathrm{mg}$ in $1 \mathrm{~kg} \mathrm{CE}-2$ ) or $5 .{ }^{*} p<0.05,{ }^{* *} p<0.01$, and ${ }^{* * *} p<0.001 \mathrm{versus}$ control at the same measurement time by parametric Dunnett's multiple comparison test.

ERK1/2 was dose-dependently inhibited in the liver (Figures 4(a) and 5(a)), gastrocnemius muscle (Figure 4(b)) and soleus muscle (Figure 5(b)), and epididymal adipose tissue (EAT, Figures 4(c) and 5(c)) by both RO5126766 and RO4987655. RO5126766 administered at $0.86 \mathrm{mg}$ in $1 \mathrm{~kg}$ CE2 or RO498655 administered at $4 \mathrm{mg}$ in $1 \mathrm{~kg}$ CE- 2 resulted in much higher inhibition of $\mathrm{pERK} 1 / 2$ in all tested tissues than was observed in PBMCs (Supplemental Figure S1).

3.3. Hyperinsulinemic-Euglycemic Glucose Clamp Test. To explore the mode of action through which MEK inhibition lowers glucose, a dosage of either $2 \mathrm{mg}$ of RO5126766 or 


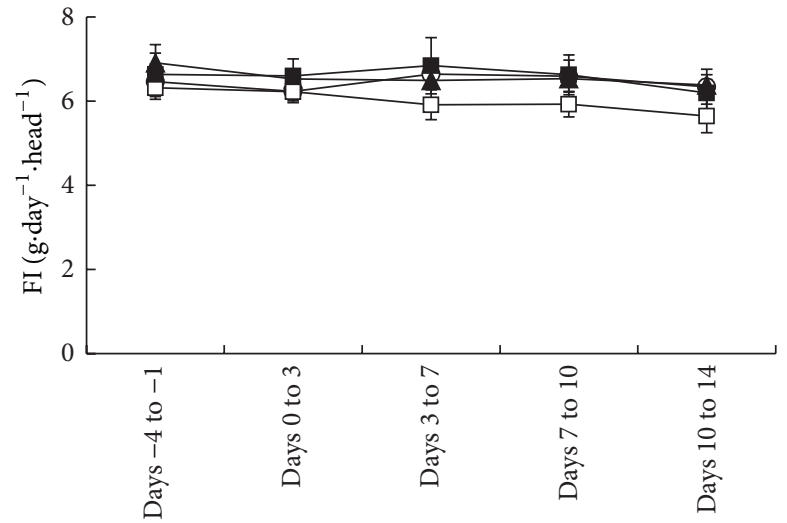

(a)

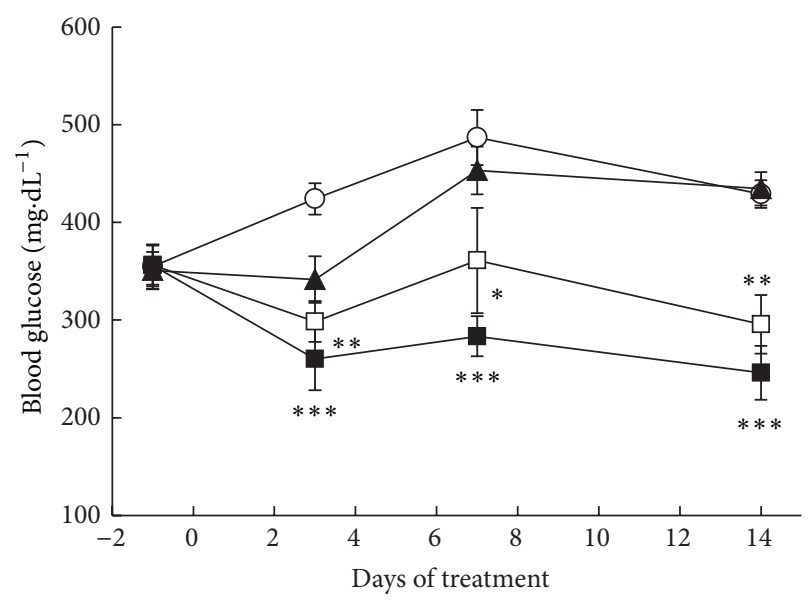

(c)

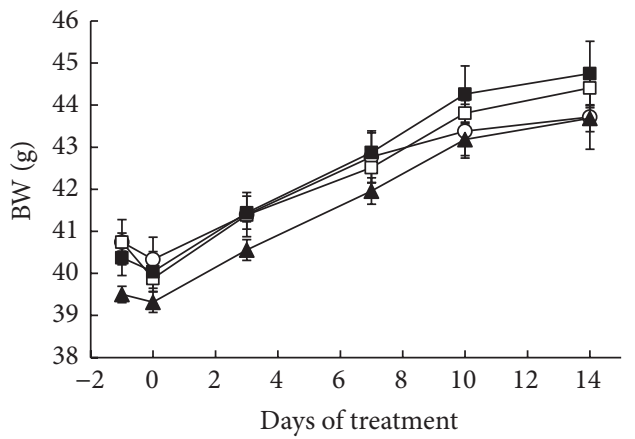

(b)

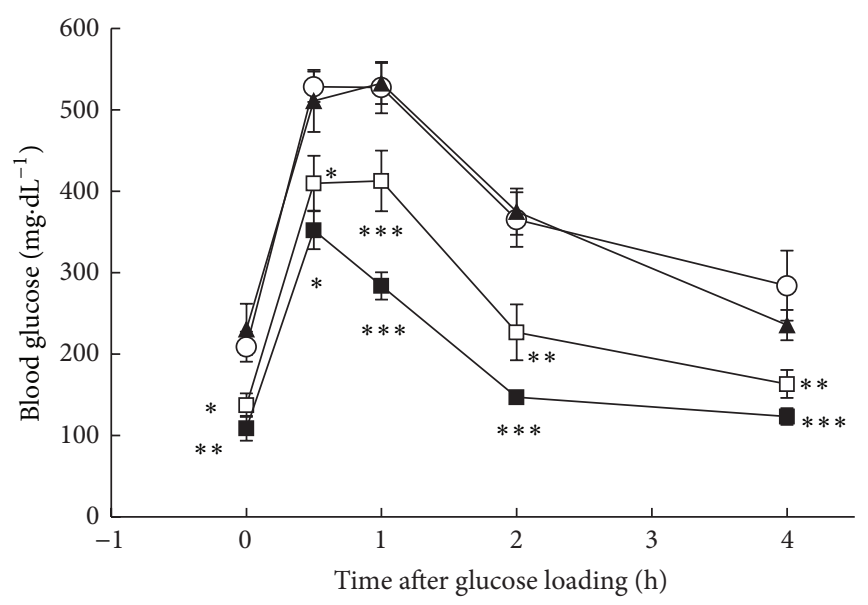

(d)

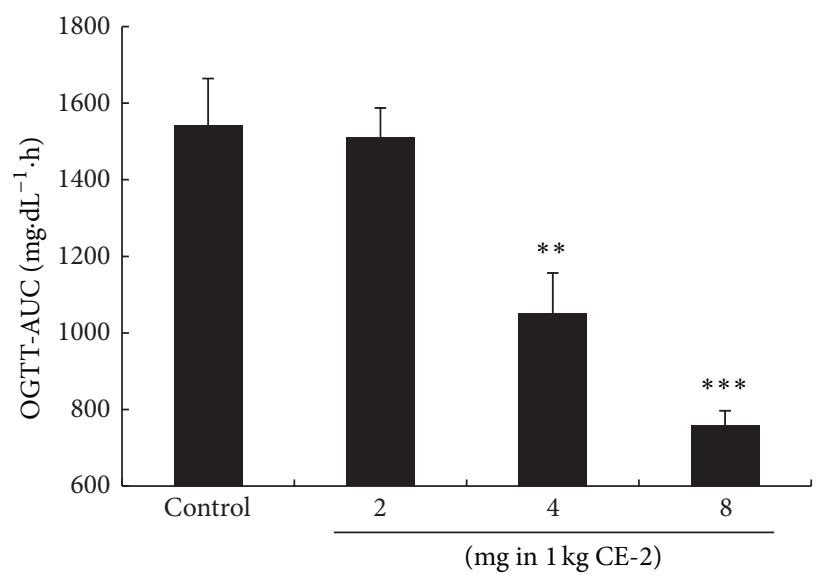

(e)

Figure 3: Effects of RO4987655 on (a) food intake (FI), (b) body weight (BW), (c) blood glucose, (d) glucose excursion, and (e) AUC during the oral glucose tolerance test (OGTT) in $d b / d b$ mice, with RO4987655 administered for 14 days as a dietary admixture with dosages as indicated: open circle, $0 \mathrm{mg}$ in $1 \mathrm{~kg}$ CE-2; closed triangle, $2 \mathrm{mg}$ in $1 \mathrm{~kg}$ CE-2; open rectangle, $4 \mathrm{mg}$ in $1 \mathrm{~kg}$ CE-2; and closed rectangle, $8 \mathrm{mg}$ in $1 \mathrm{~kg}$ CE-2. Data are expressed as mean \pm SEM, $n=6 .{ }^{*} p<0.05,{ }^{* *} p<0.01$, and ${ }^{* * *} p<0.001$ versus control $(0 \mathrm{mg}$ in $1 \mathrm{~kg}$ CE- 2$)$ at the same measurement time by parametric Dunnett's multiple comparison test. 

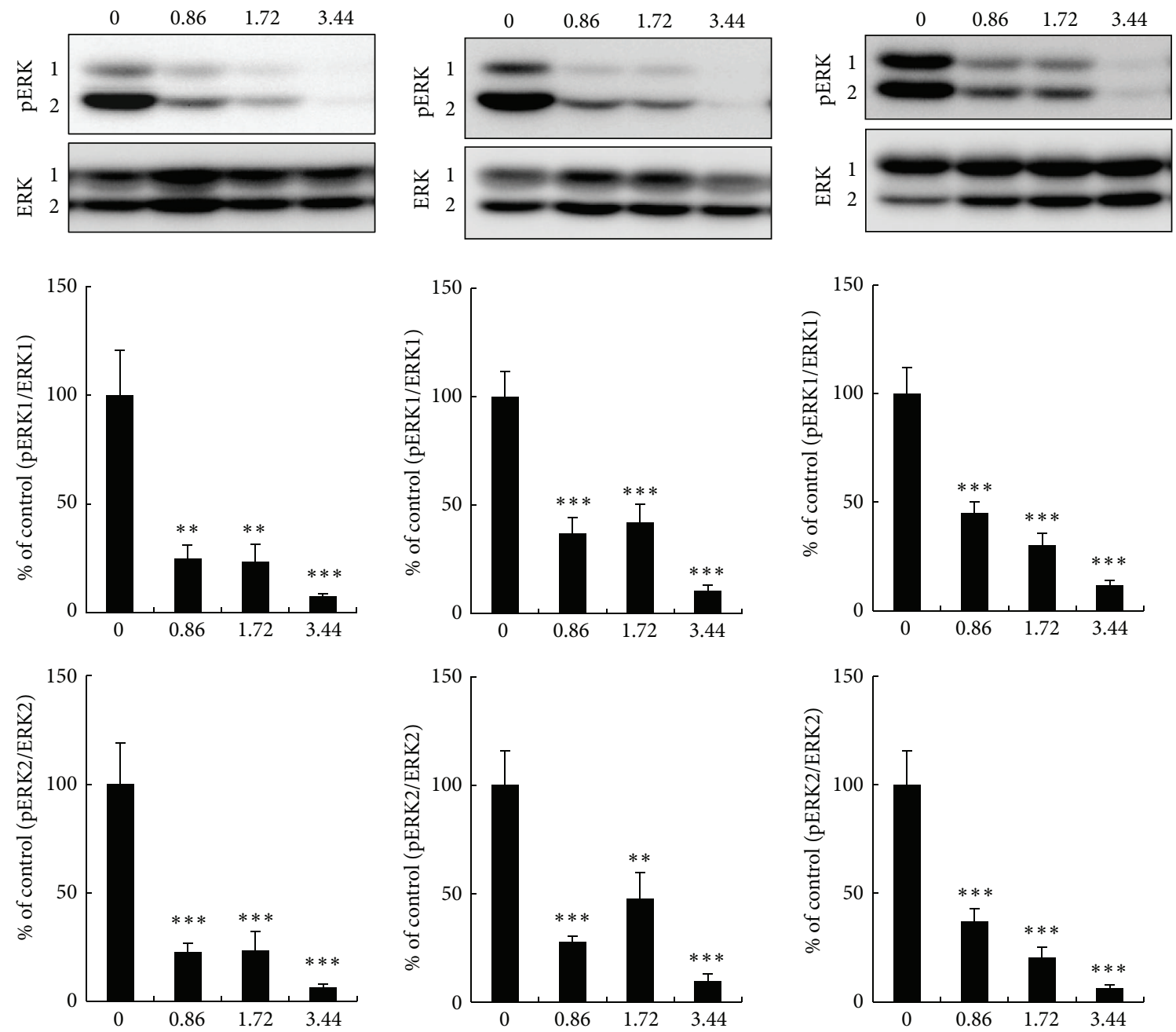

(a)

(b)

(c)

FIGURE 4: Effects of RO5126766 on pERK1/2 in (a) liver, (b) gastrocnemius muscle, and (c) epididymal adipose tissue from $d b / d b$ mice. RO5126766 was administered as a dietary admixture at the indicated dosages ( $\mathrm{mg}$ in $1 \mathrm{~kg}$ CE-2; numbers on the $x$-axis) for 17 days. Representative blots from each type of tissue are shown at the top of the figures. Data are expressed as mean \pm SEM, $n=5$ or 6 (control group, $0 \mathrm{mg}$ in $1 \mathrm{~kg} \mathrm{CE}-2) .{ }^{* *} p<0.01,{ }^{* * *} p<0.001$ versus control by parametric Dunnett's multiple comparison test.

$8 \mathrm{mg}$ of RO4987655 in $1 \mathrm{~kg}$ CE-2 was administered to $\mathrm{db} / \mathrm{db}$ mice for 9-11 days, and $200 \mathrm{mg}$ of pioglitazone in $1 \mathrm{~kg}$ CE-2 was administered to a separate group of mice as a reference. A hyperinsulinemic-euglycemic glucose clamp test was conducted after $4 \mathrm{~h}$ fasting on the day of the clamp test. No decrease in FI or BW was observed during the treatment (data not shown).

FBG was significantly decreased by administration of RO5126766, and GIR was significantly increased to $26.8 \pm$ $2.7 \mathrm{mg} \cdot \mathrm{kg}^{-1} \cdot \mathrm{min}^{-1}$ compared to that of control $(9.5 \pm$ $2.1 \mathrm{mg} \cdot \mathrm{kg}^{-1} \cdot \mathrm{min}^{-1}$ ) (Table 1), suggesting that IR was improved. EGP from mice treated with RO5126766 was significantly decreased from $16.8 \pm 3.7 \mathrm{mg} \cdot \mathrm{kg}^{-1} \cdot \mathrm{min}^{-1}$ in control mice to $6.8 \pm 2.3 \mathrm{mg} \cdot \mathrm{kg}^{-1} \cdot \mathrm{min}^{-1}$ (Table 1 ), suggesting improvement of IR in the liver. Decreased EGP (16.8 - 6.8 $=10.0 \mathrm{mg} \cdot \mathrm{kg}^{-1} \cdot \mathrm{min}^{-1}$ ) by $\mathrm{RO} 5126766$ administration accounted for around $58 \%$ of the increased GIR $\left(26.8-9.5=17.3 \mathrm{mg} \cdot \mathrm{kg}^{-1} \cdot \mathrm{min}^{-1}\right)$. Moreover, plasma insulin level at the end of the clamp test was comparable between the three groups (control, $43.7 \pm 3.5 \mathrm{ng} \cdot \mathrm{mL}^{-1}$; RO5126766, $50.4 \pm$ $6.4 \mathrm{ng} \cdot \mathrm{mL}^{-1}$; and pioglitazone, $41.6 \pm 8.8 \mathrm{ng} \cdot \mathrm{mL}^{-1}$; Table 1 ), which supports the improvement of IR by RO5126766.

Similar results were obtained when RO4987655 was administered to mice. FBG was significantly decreased and GIR was significantly increased to $28.2 \pm 3.7 \mathrm{mg} \cdot \mathrm{kg}^{-1} \cdot \mathrm{min}^{-1}$ compared to that of control $\left(19.0 \pm 1.3 \mathrm{mg} \cdot \mathrm{kg}^{-1} \cdot \mathrm{min}^{-1}\right)$ (Table 2), suggesting that RO4987655 improved IR as well. EGP was not statistically significantly different $(p=0.1779)$ but tended to decrease, from $11.9 \pm 1.8 \mathrm{mg} \cdot \mathrm{kg}^{-1} \cdot \mathrm{min}^{-1}$ in control mice to $6.5 \pm 1.9 \mathrm{mg} \cdot \mathrm{kg}^{-1} \cdot \mathrm{min}^{-1}$ (Table 2), suggesting that the IR in the liver was improved by RO4987655. Decreased EGP $\left(11.9-6.5=5.4 \mathrm{mg} \cdot \mathrm{kg}^{-1} \cdot \mathrm{min}^{-1}\right)$ by RO4987655 administration accounted for around $59 \%$ of the increased GIR $\left(28.2-19.0=9.2 \mathrm{mg} \cdot \mathrm{kg}^{-1} \cdot \mathrm{min}^{-1}\right)$. Plasma insulin level at 

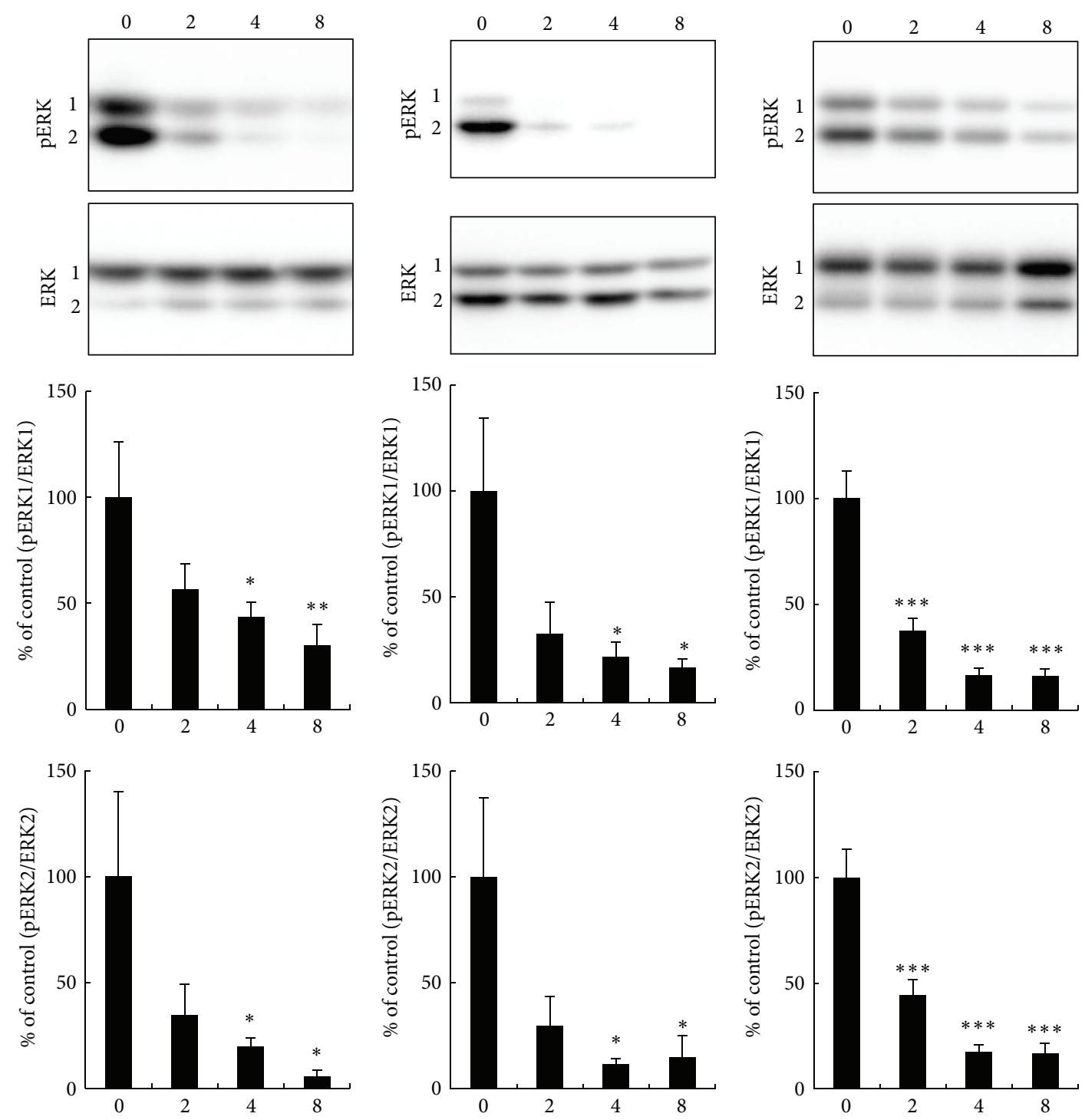

(a)

(b)

(c)

FIGURE 5: Effects of RO4987655 on pERK1/2 in (a) liver, (b) soleus muscle, and (c) epididymal adipose tissue from $d b / d b$ mice. RO4987655 was administered as a dietary admixture at the indicated dosages ( $\mathrm{mg}$ in $1 \mathrm{~kg} \mathrm{CE}-2$; numbers on the $x$-axis) for 17 days. Representative blots from each type of tissue are shown at the top of the figures. Data are expressed as mean \pm SEM, $n=6 .{ }^{*} p<0.05,{ }^{* *} p<0.01$, and ${ }^{* * *} p<0.001$ versus control group ( $0 \mathrm{mg}$ in $1 \mathrm{~kg}$ CE-2) by parametric Dunnett's multiple comparison test.

the end of the clamp test was comparable between the control group $\left(40.1 \pm 2.6 \mathrm{ng} \cdot \mathrm{mL}^{-1}\right)$ and the $\mathrm{RO} 4987655$-treated group $\left(28.1 \pm 4.6 \mathrm{ng} \cdot \mathrm{mL}^{-1}\right)$ (Table 2).

Approximately $60 \%$ of the increase in GIR following the administration of either RO4987655 or RO5126766 is explained by the suppression of EGP, which appears to be mainly caused by MEK $1 / 2$ inhibition improving IR in the liver.

Similarly, decreased FBG and increased GIR were observed in mice treated with pioglitazone (average dose, $30 \mathrm{mg} \cdot \mathrm{kg}^{-1} \cdot \mathrm{day}^{-1}$ ). The percentages of decreased EGP that accounted for the increased GIR were $88 \%$ for RO5126766 (Table 1) and 57\% for RO4987655, respectively (Table 2).
3.4. Suppression of MEK1 Protein in the Liver by AdenovirusMediated shRNA of Mek1 (Map2k1) Expression and Its Effect on Blood Glucose. Because the hyperinsulinemic-euglycemic glucose clamp test revealed that the tissue in which IR was most improved by MEK inhibitions would be the liver, we hypothesized that suppression of MEK1 protein expression in the liver would lead to decreased blood glucose in $d b / d b$ mice. We tested the hypothesis by using adenovirus-mediated shRNA expression of $M e k 1$ in $d b / d b$ mice.

Three days after administration of an adenovirus which expressed shRNA of Mek1 $\left(5 \times 10^{10} \mathrm{ifu} \cdot \mathrm{kg}^{-1}\right)$, blood glucose tended to be lower than that in the group treated with scrambled shRNA (scramble-treated group) (Figure 6(a)), 


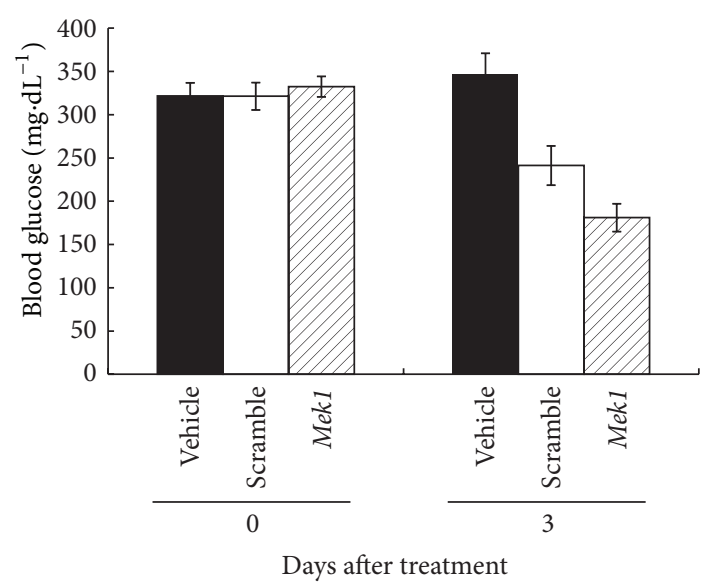

(a)

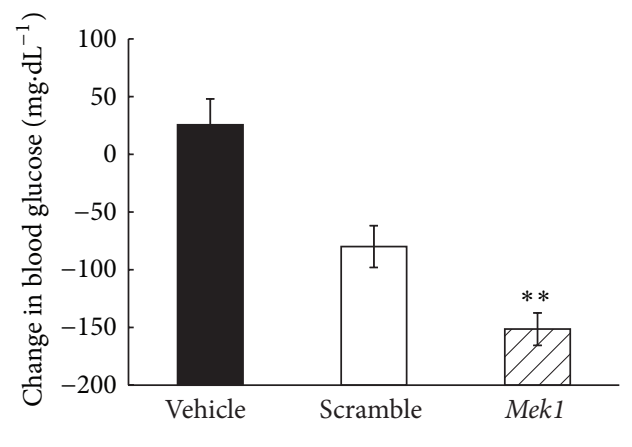

(b)

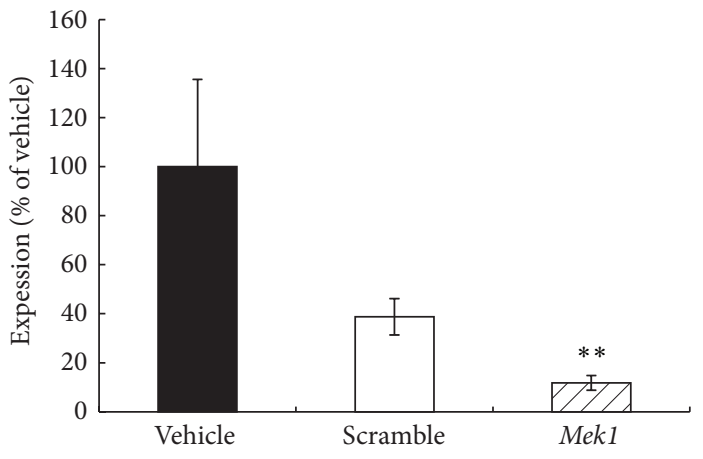

(c)

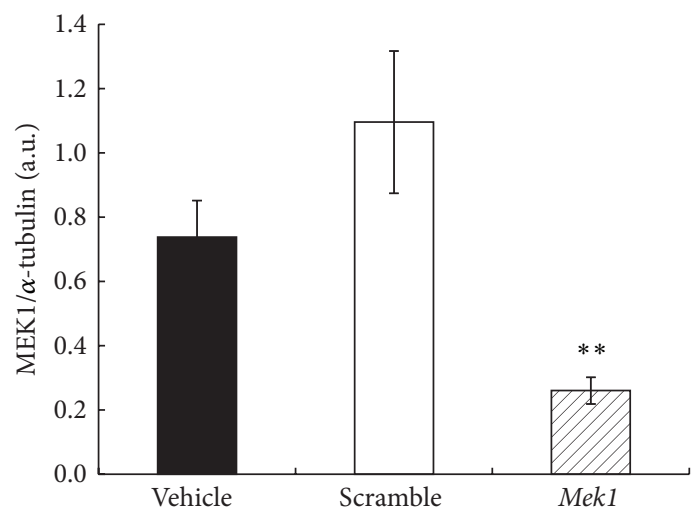

(e)

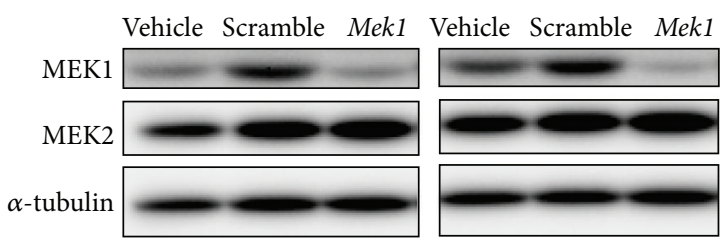

(d)

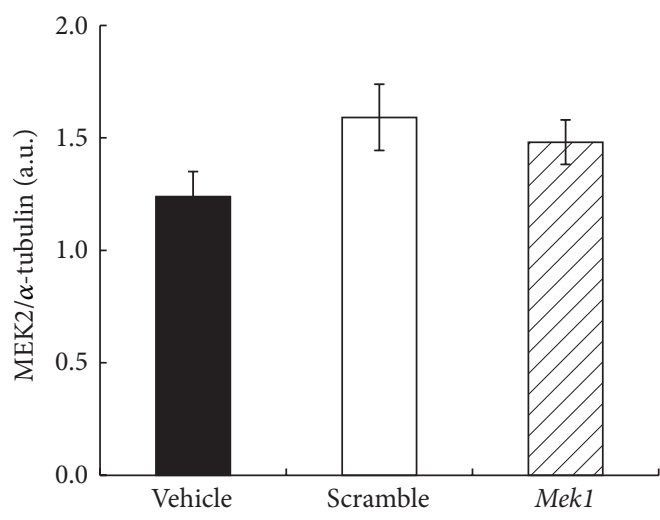

(f)

FIGURE 6: Effects of Mekl (Map2k1) silencing by adenovirus-mediated shRNA expression of Mekl in $d b / d b$ mice on (a, b) blood glucose, (c) Mek1 mRNA expression level in the liver, (d) representative blots of MEK1 and MEK2 protein in the liver, and (e, f) MEK1 and MEK2 protein expression level in the liver. Data are expressed as mean \pm SEM, $n=6 .^{* *} p<0.01$ versus scramble by Welch's test. The lanes were run on the same gel but were noncontiguous. Black bars, vehicle-treated group; white bars, scramble-treated group; hatched bars, Mekl-silenced group.

and the change in blood glucose was significantly lower than that of the scramble-treated group (Figure 6(b)). Mek1 mRNA level determined by qRT-PCR and MEK1 protein expression determined by western blotting in the liver were decreased to $20-30 \%$ of those of scramble-treated mice (Figures 6(c)6(e)). A compensatory increase in MEK2 protein expression was not observed (Figures 6(d) and 6(f)). There were no effects on FI and BW gain by the adenovirus-mediated shRNA expression (data not shown).

\section{Discussion}

We showed here that RO5126766 and RO4987655 exerted antidiabetic effects in $d b / d b$ mice. These antidiabetic effects were not due to "off-target" effects of these compounds because (i) these compounds are structurally different (Figure 1), (ii) RO5126766 is specific to Raf/MEK and $10 \mu \mathrm{mol} \cdot \mathrm{L}^{-1}$ RO5126766 did not inhibit any of the 256 other kinases in the Ambit KINOME scan panel $[24,26]$, (iii) RO4987655 
TABLE 1: Blood glucose level, glucose infusion rate (GIR), and endogenous glucose production (EGP) of RO5126766-treated $d b / d b$ mice in the hyperinsulinemic-euglycemic clamp test.

\begin{tabular}{|c|c|c|c|}
\hline & Control & $\begin{array}{c}\text { RO5126766 } \\
(2 \mathrm{mg} \text { in } 1 \mathrm{~kg} \mathrm{CE}-2)\end{array}$ & $\begin{array}{c}\text { Pioglitazone } \\
(200 \mathrm{mg} \text { in } 1 \mathrm{~kg} \text { CE- } 2)\end{array}$ \\
\hline$n$ & 10 & 10 & 5 \\
\hline Blood glucose $\left(\mathrm{mg} \cdot \mathrm{dL}^{-1}\right)(4 \mathrm{~h}$ fasted $)$ & $272.9 \pm 30.6$ & $141.2 \pm 12.9^{* * *}$ & $104.6 \pm 12.4^{* * *}$ \\
\hline Blood glucose $\left(\mathrm{mg} \cdot \mathrm{dL}^{-1}\right)^{9}$ & $121.3 \pm 8.7$ & $109.5 \pm 2.7$ & $107.9 \pm 3.0$ \\
\hline $\operatorname{GIR}\left(\mathrm{mg} \cdot \mathrm{kg}^{-1} \cdot \mathrm{min}^{-1}\right)^{9}$ & $9.5 \pm 2.1$ & $26.8 \pm 2.7^{* * *}$ & $29.7 \pm 5.7^{* * *}$ \\
\hline $\mathrm{EGP}\left(\mathrm{mg} \cdot \mathrm{kg}^{-1} \cdot \mathrm{min}^{-1}\right)$ & $16.8 \pm 3.7$ & $6.8 \pm 2.3^{*}$ & $-0.9 \pm 3.0^{* *}$ \\
\hline Plasma insulin $\left(\mathrm{ng} \cdot \mathrm{mL}^{-1}\right)$ & $43.7 \pm 3.5$ & $50.4 \pm 6.4^{\mathrm{a}}$ & $41.6 \pm 8.8$ \\
\hline
\end{tabular}

Data are expressed as mean \pm SEM.

${ }^{9}$ Mean values of last $60 \mathrm{~min}$ on clamp.

${ }^{*} p<0.05,{ }^{* *} p<0.01$, and ${ }^{* *} p<0.001$ versus control by parametric Dunnett's multiple comparison test.

${ }^{\mathrm{a}} n=9$.

TABLE 2: Blood glucose level, glucose infusion rate (GIR), and endogenous glucose production (EGP) of RO4987655-treated $d b / d b$ mice in the hyperinsulinemic-euglycemic clamp test.

\begin{tabular}{lccr}
\hline & Control & $\begin{array}{c}\text { RO4987655 } \\
(8 \mathrm{mg} \text { in } 1 \mathrm{~kg} \text { in CE-2) }\end{array}$ & $\begin{array}{c}\text { Pioglitazone } \\
(200 \mathrm{mg} \text { in } 1 \mathrm{~kg} \mathrm{CE}-2)\end{array}$ \\
\hline$n$ & 10 & 9 & 10 \\
Blood glucose $\left(\mathrm{mg} \cdot \mathrm{dL}^{-1}\right)(4 \mathrm{~h}$ fasted $)$ & $228.4 \pm 34.7$ & $125.4 \pm 11.2^{* *}$ & $142.1 \pm 16.0^{*}$ \\
Blood glucose $\left(\mathrm{mg} \cdot \mathrm{dL}^{-1}\right)$ & $103.4 \pm 3.3$ & $108.7 \pm 1.5$ & $108.1 \pm 4.6$ \\
GIR $\left(\mathrm{mg} \cdot \mathrm{kg}^{-1} \cdot \mathrm{min}^{-1}\right)^{g}$ & $19.0 \pm 1.3$ & $28.2 \pm 3.7^{*}$ & $35.8 \pm 2.0^{* * *}$ \\
EGP $\left(\mathrm{mg} \cdot \mathrm{kg}^{-1} \cdot \mathrm{min}^{-1}\right)$ & $11.9 \pm 1.8$ & $6.5 \pm 1.9^{\S}$ & $2.3 \pm 2.6^{* *}$ \\
Plasma insulin $\left(\mathrm{ng} \cdot \mathrm{mL}^{-1}\right)$ & $40.1 \pm 2.6^{\mathrm{a}}$ & $28.1 \pm 4.6^{\mathrm{b}}$ & $\mathrm{ND}$ \\
\hline
\end{tabular}

Data are expressed as mean \pm SEM.

${ }^{M}$ Mean values of last 60 min on clamp.

${ }^{*} p<0.05,{ }^{* *} p<0.01$, and ${ }^{* * *} p<0.001$ versus control by parametric Dunnett's multiple comparison test.

${ }^{\S} p=0.1779$ versus control by parametric Dunnett's multiple comparison test.

$\mathrm{ND}$, not determined.

${ }^{\mathrm{a}} n=5$ and ${ }^{\mathrm{b}} n=3$.

is specific to $\mathrm{MEK} 1 / 2$ and $10 \mu \mathrm{mol} \cdot \mathrm{L}^{-1} \mathrm{RO} 4987655 \mathrm{did}$ not inhibit any of the 400 other kinases [28], and (iv) there were no toxic signs in $d b / d b$ mice treated with these compounds for 17 days (Supplemental Tables S2 and S3). These results are further supported by similar results obtained from KKAy mice (Supplemental Figure S2), which is another T2D model animal that has a different genetic background from $d b / d b$ mice but which shows similar phenotypes, such as obesity, hyperglycemia, and hyperinsulinemia $[35,36]$. Taken together, these results strongly suggest that MEK inhibition could lower blood glucose in T2D.

The two MEK inhibitors used in this experiment did not induce much BW gain in either $d b / d b$ or KK-Ay mice (Figures 2 and 3, Supplemental Figures S2 and S3). In addition, they did not show any effect on the expression of several adipogenic genes that are downstream of the PPAR $\gamma$ pathway (Supplemental Figure S6) nor did they have any effect on insulinotropic action (Supplemental Figure S5). We also did not observe any direct insulinotropic action on INS-1E cells by these compounds (data not shown).

The results from the hyperinsulinemic-euglycemic glucose clamp test in the animals treated with the MEK inhibitors strongly suggested whole-body improvement of IR similar to that seen in mice treated with pioglitazone (Tables 1 and 2). Furthermore, with both compounds, about
$60 \%$ of the increased GIR was accounted for by decreased EGP (Tables 1 and 2), suggesting that the liver would be the tissue most responsive to whole-body improvement of IR by MEK inhibition. However, in compound-treated mice, dosedependent inhibition of pERK1/2 was also observed in other insulin-responsive tissues, such as soleus muscle, and EAT (Figures 4 and 5), which suggests that although the main responsive tissue is liver, peripheral tissues, that is, skeletal muscle and adipose tissue, would contribute to amelioration of the remaining part of whole-body IR in vivo. We observed a tendency for Akt Ser ${ }^{473}$ phosphorylation to increase in soleus muscle and EAT, as well as in the liver from $d b / d b$ mice after administration of both compounds (data not shown). The underlying molecular mechanisms need to be analyzed in further detail to understand the exact relationships between MEK inhibition and amelioration of IR, which will lead to deeper insights into alternative therapeutic strategies for treating IR or T2D.

Because the improvement of IR was achieved mainly in the liver, we confirmed whether suppressing MEK1 protein expression in the liver of $d b / d b$ mice would lead to decreased blood glucose. We found that adenovirus-mediated shRNA expression of Mek1 could suppress the MEK1 protein expression only in the liver (not in skeletal muscle, data not shown). Administration of adenovirus-mediated shRNA 
of Mek1 reduced blood glucose (Figures 6(a) and 6(b)) accompanied by lower levels of Mek1 mRNA and protein expression in the liver than were observed in the scrambletreated group (Figures 6(c)-6(e)). These results strongly supported our hypothesis that lowering MEK1 activity in the liver would lead to decreased blood glucose. However, in our western blot analysis, phosphorylation of ERK1/2 in the liver was not decreased by the administration of shRNA of Mekl (data not shown). This may be due to phosphorylation by intact MEK2 or by the remaining part of MEK1 activity, because MEK1 protein was not completely inhibited (Figures $6(\mathrm{~d})$ and $6(\mathrm{e}))$. The relatively low degree of decrease in blood glucose levels that was achieved by Mek1 silencing as compared to the decrease in blood glucose achieved by MEK inhibitors may be because the inhibitory effect of a compound administered systemically was exerted not only in the liver but also in skeletal muscle and EAT, as we have suggested above. In the group treated with scrambled shRNA, the mRNA level of Mekl in the liver decreased to less than half that of the vehicle-treated group (Figure 6(c)); however, MEK1 protein expression level in the liver did not decrease, as shown in Figures 6(d) and 6(e). We do not know the exact mechanism through which the scrambled shRNA decreased blood glucose and Mek1 mRNA in this particular experiment in vivo. One possible explanation is that a more significant reduction in Mekl mRNA expression is necessary for a decrease in MEK1 protein; another possible explanation is that the decrease in blood glucose by an uncertain mechanism of scrambled shRNA may lead to a decrease in the level of Mekl mRNA expression. Whatever the case may be, the fact that there was no reduction in MEK1 protein by the scrambled shRNA suggests that the effect of Mekl mRNA reduction on blood glucose can be considered to be minimal.

In the present study, we evaluated MEK inhibition as an antidiabetic drug target using a T2D animal model, the $d b / d b$ mouse. Using pharmacological intervention with two structurally different MEK inhibitors (RO5126766 and RO4987655) and RNA interference intervention with adenovirus-mediated Mek1 shRNA expression, we confirmed that inhibition of MEK activity and suppression of MEK1 protein expression both lowered blood glucose through the amelioration of IR.

\section{Conclusions}

From the current study, we conclude that MEK could be a potential therapeutic target for T2D treatment. The therapeutic potential of MEK inhibition needs to be examined in clinical trials with T2D patients, and further study is needed to explore the exact mechanisms through which inhibiting the MEK1 signaling pathway improves IR, especially in the liver, in order to avoid undesirable adverse events by MEK inhibition [37, 38].

\section{Abbreviations}

Akt: Protein kinase B

AUC: Area under the curve
BW: Body weight

EAT: $\quad$ Epididymal adipose tissue

EGP: Endogenous glucose production

ERK: Extracellular signal-regulated kinase

FBG: $\quad$ Fasting blood glucose

FI: $\quad$ Food intake

GIR: Glucose infusion rate

ifu: Infectious units

IR: Insulin resistance

IRS-1: Insulin receptor substrate-1

MAPK: Mitogen-activated protein kinase

MEK: Mitogen-activated protein kinase kinase

OGTT: Oral glucose tolerance test

PBMC: Peripheral blood mononuclear cells

PD: $\quad$ Pharmacodynamics

pERK1/2: Phosphorylation of ERK1/2

PI 3-K: Phosphoinositide 3-kinase

PPAR: Peroxisome proliferator-activated receptor

qRT-PCR: Quantitative real-time polymerase chain reaction

T2D: $\quad$ Type 2 diabetes.

\section{Conflict of Interests}

Atsunori Ueyama, Nobuhiro Ban, Masanori Fukazawa, Tohru Hirayama, Minako Takeda, Hiroyasu Muramatsu, Masaki Hoshino, Marii Yamamoto, Masao Matsuo, Yuka Kawashima, Tatsuhiko Iwase, Takehisa Kitazawa, Youichi Kushima, and Yoshiki Kawabe are employees of Chugai Pharmaceutical Co., Ltd. Tatsuo Yata is an employee of Chugai Research Institute for Medical Science. Yuichiro Yamada is a professor of the Department of Endocrinology, Diabetes and Geriatric Medicine, Akita University School of Medicine. The authors declare that there is no conflict of interests regarding the publication of this paper.

\section{Authors' Contribution}

Atsunori Ueyama, Nobuhiro Ban, Tatsuhiko Iwase, Takehisa Kitazawa, Youichi Kushima, and Yoshiki Kawabe conceived of and designed this research; Masanori Fukazawa, Minako Takeda, Tatsuo Yata, Marii Yamamoto, and Hiroyasu Muramatsu performed animal experiments; Tohru Hirayama, Nobuhiro Ban, Masaki Hoshino, and Hiroyasu Muramatsu prepared adenovirus-expressed shRNA of Mekl and performed animal experiments; Atsunori Ueyama, Masaki Hoshino, Yuka Kawashima, and Masao Matsuo performed in vitro experiments; and Nobuhiro Ban, Takehisa Kitazawa, Youichi Kushima, Yuichiro Yamada, and Yoshiki Kawabe approved the final version of this paper.

\section{Acknowledgments}

The authors thank Eiji Kaneko, Takako Sakamoto, Manabu Hirabayashi, and Mio Kawai (employees of Chugai Research Institute for Medical Science) for assistance with conducting the glucose clamp study, Kazuhisa Ozeki (employee of Chugai Pharmaceutical Co., Ltd.) for the PK study, and 
Naoaki Murao (employee of Chugai Pharmaceutical Co., Ltd.) for measurement of $\left[\mathrm{U}_{-}{ }^{13} \mathrm{C}\right]$ glucose. They also thank Yuuji Ishikawa and Masao Kuroi (employees of Chugai Pharmaceutical Co., Ltd.) for arrangement of the compounds.

\section{References}

[1] T. Nagata, M. Fukazawa, K. Honda et al., "Selective SGLT2 inhibition by tofogliflozin reduces renal glucose reabsorption under hyperglycemic but not under hypo- or euglycemic conditions in rats," American Journal of Physiology - Endocrinology and Metabolism, vol. 304, no. 4, pp. E414-E423, 2013.

[2] Y. Ohtake, T. Sato, T. Kobayashi et al., "Discovery of tofogliflozin, a novel $\mathrm{C}$-arylglucoside with an $\mathrm{O}$-spiroketal ring system, as a highly selective sodium glucose cotransporter 2 (SGLT2) inhibitor for the treatment of type 2 diabetes," Journal of Medicinal Chemistry, vol. 55, no. 17, pp. 7828-7840, 2012.

[3] H. Tilg and A. R. Moschen, "Insulin resistance, inflammation, and non-alcoholic fatty liver disease," Trends in Endocrinology and Metabolism, vol. 19, no. 10, pp. 371-379, 2008.

[4] K. Siddle, "Signalling by insulin and IGF receptors: supporting acts and new players," Journal of Molecular Endocrinology, vol. 47, no. 1, pp. R1-R10, 2011.

[5] K. Cusi, K. Maezono, A. Osman et al., "Insulin resistance differentially affects the PI 3-kinase- and MAP kinase-mediated signaling in human muscle," The Journal of Clinical Investigation, vol. 105, no. 3, pp. 311-320, 2000.

[6] C. M. Crews, A. Alessandrini, and R. L. Erikson, "The primary structure of MEK, a protein kinase that phosphorylates the ERK gene product," Science, vol. 258, no. 5081, pp. 478-480, 1992.

[7] D. R. Alessi, Y. Saito, D. G. Campbell et al., "Identification of the sites in MAP kinase kinase-1 phosphorylated by p74raf-1," The EMBO Journal, vol. 13, no. 7, pp. 1610-1619, 1994.

[8] A. Dunaif, J. Xia, C.-B. Book, E. Schenker, and Z. Tang, "Excessive insulin receptor serine phosphorylation in cultured fibroblasts and in skeletal muscle. A potential mechanism for insulin resistance in the polycystic ovary syndrome," Journal of Clinical Investigation, vol. 96, no. 2, pp. 801-810, 1995.

[9] A. Krook, M. Björnholm, D. Galuska et al., "Characterization of signal transduction and glucose transport in skeletal muscle from type 2 diabetic patients," Diabetes, vol. 49, no. 2, pp. 284292, 2000.

[10] A. A. Osman, M. Pendergrass, J. Koval et al., "Regulation of MAP kinase pathway activity in vivo in human skeletal muscle," The American Journal of Physiology-Endocrinology and Metabolism, vol. 278, no. 6, pp. E992-E999, 2000.

[11] M. Fujishiro, Y. Gotoh, H. Katagiri et al., "Three mitogenactivated protein kinases inhibit insulin signaling by different mechanisms in 3T3-L1 adipocytes," Molecular Endocrinology, vol. 17, no. 3, pp. 487-497, 2003.

[12] Y. Izawa, M. Yoshizumi, Y. Fujita et al., "ERK1/2 activation by angiotensin II inhibits insulin-induced glucose uptake in vascular smooth muscle cells," Experimental Cell Research, vol. 308, no. 2, pp. 291-299, 2005.

[13] J. Imai, H. Katagiri, T. Yamada et al., "Regulation of pancreatic beta cell mass by neuronal signals from the liver," Science, vol. 322, no. 5905, pp. 1250-1254, 2008.

[14] G. Pagès, S. Guérin, D. Grall et al., "Defective thymocyte maturation in p44 MAP kinase (Erk 1) knockout mice," Science, vol. 286, no. 5443, pp. 1374-1377, 1999.
[15] C. Mazzucchelli, C. Vantaggiato, A. Ciamei et al., "Knockout of ERK1 MAP kinase enhances synaptic plasticity in the striatum and facilitates striatal-mediated learning and memory," Neuron, vol. 34, no. 5, pp. 807-820, 2002.

[16] F. Bost, M. Aouadi, L. Caron et al., "The extracellular signalregulated kinase isoform ERK1 is specifically required for in vitro and in vivo adipogenesis," Diabetes, vol. 54, no. 2, pp. 402411, 2005.

[17] J. C. Selcher, T. Nekrasova, R. Paylor, G. E. Landreth, and J. D. Sweatt, "Mice lacking the ERK1 isoform of MAP kinase are unimpaired in emotional learning," Learning and Memory, vol. 8, no. 1, pp. 11-19, 2001.

[18] S. Giroux, M. Tremblay, D. Bernard et al., "Embryonic death of Mek1-deficient mice reveals a role for this kinase in angiogenesis in the labyrinthine region of the placenta," Current Biology, vol. 9, no. 7, pp. 369-372, 1999.

[19] Y. Yao, W. Li, J. Wu et al., "Extracellular signal-regulated kinase 2 is necessary for mesoderm differentiation," Proceedings of the National Academy of Sciences of the United States of America, vol. 100, no. 22, pp. 12759-12764, 2003.

[20] M. K. Saba-El-Leil, F. D. J. Vella, B. Vernay et al., "An essential function of the mitogen-activated protein kinase Erk2 in mouse trophoblast development," EMBO Reports, vol. 4, no. 10, pp. 964-968, 2003.

[21] N. Hatano, Y. Mori, M. Oh-hora et al., "Essential role for ERK2 mitogen-activated protein kinase in placental development," Genes to Cells, vol. 8, no. 11, pp. 847-856, 2003.

[22] L. Lee, H. Niu, R. Rueger et al., "The safety, tolerability, pharmacokinetics, and pharmacodynamics of single oral doses of CH4987655 in healthy volunteers: target suppression using a biomarker," Clinical Cancer Research, vol. 15, no. 23, pp. 7368$7374,2009$.

[23] L. Zimmer, F. Barlesi, M. Martinez-Garcia et al., "Phase I expansion and pharmacodynamic study of the oral MEK inhibitor RO4987655 (CH4987655) in selected patients with advanced cancer with RAS-RAF mutations," Clinical Cancer Research, vol. 20, no. 16, pp. 4251-4261, 2014.

[24] N. Ishii, N. Harada, E. W. Joseph et al., "Enhanced inhibition of ERK signaling by a novel allosteric MEK inhibitor, CH5126766, that suppresses feedback reactivation of RAF activity," Cancer Research, vol. 73, no. 13, pp. 4050-4060, 2013.

[25] T. Aoki, I. Hyohdoh, N. Furuichi et al., "The sulfamide moiety affords higher inhibitory activity and oral bioavailability to a series of coumarin dual selective RAF/MEK inhibitors," Bioorganic and Medicinal Chemistry Letters, vol. 23, no. 23, pp. 6223-6227, 2013.

[26] M. Martinez-Garcia, U. Banerji, J. Albanell et al., "First-inhuman, phase I dose-escalation study of the safety, pharmacokinetics, and pharmacodynamics of RO5126766, a first-in-class dual MEK/RAF inhibitor in patients with solid tumors," Clinical Cancer Research, vol. 18, no. 17, pp. 4806-4819, 2012.

[27] K. Honda, N. Yamamoto, H. Nokihara et al., "Phase I and pharmacokinetic/pharmacodynamic study of RO5126766, a first-in-class dual Raf/MEK inhibitor, in Japanese patients with advanced solid tumors," Cancer Chemotherapy and Pharmacology, vol. 72, no. 3, pp. 577-584, 2013.

[28] Y. Isshiki, Y. Kohchi, H. Iikura et al., "Design and synthesis of novel allosteric MEK inhibitor CH4987655 as an orally available anticancer agent," Bioorganic and Medicinal Chemistry Letters, vol. 21, no. 6, pp. 1795-1801, 2011.

[29] S. M. Furler, G. S. Zelenka, and E. W. Kraegen, "Development and testing of a simple algorithm for a glucose clamp," Medical 
and Biological Engineering and Computing, vol. 24, no. 4, pp. 365-370, 1986.

[30] E. Rogatsky, H. Jayatillake, G. Goswami, V. Tomuta, and D. Stein, "Sensitive LC MS quantitative analysis of carbohydrates by $\mathrm{Cs}^{+}$attachment," Journal of the American Society for Mass Spectrometry, vol. 16, no. 11, pp. 1805-1811, 2005.

[31] R. Bergeron, S. F. Previs, G. W. Cline et al., "Effect of 5 -aminoimidazole-4-carboxamide-1- $\beta$-D-ribofuranoside infusion on in vivo glucose and lipid metabolism in lean and obese zucker rats," Diabetes, vol. 50, no. 5, pp. 1076-1082, 2001.

[32] N. Ban, Y. Yamada, Y. Someya et al., "Activating transcripton factor-2 is a positive regulator in CaM kinase IV-induced human insulin gene expression," Diabetes, vol. 49, no. 7, pp. 1142-1148, 2000.

[33] N. Ban, Y. Yamada, Y. Someya et al., "Hepatocyte nuclear factorlalpha recruits the transcriptional co-activator p300 on the GLUT2 gene promoter," Diabetes, vol. 51, no. 5, pp. 1409-1418, 2002.

[34] U. K. Laemmli, "Cleavage of structural proteins during the assembly of the head of bacteriophage T4," Nature, vol. 227, no. 5259, pp. 680-685, 1970.

[35] M. Nakamura and K. Yamada, "Studies on a diabetic (KK) strain of the mouse," Diabetologia, vol. 3, no. 2, pp. 212-221, 1967.

[36] K. Furuno, K. Shimakawa, and Z. Suzuoki, "Effects of nutritional factors on the development of ethanol induced fatty liver in KK and KK-Ay mice," Journal of Nutrition, vol. 105, no. 10, pp. 1263-1268, 1975.

[37] J. C. Mavropoulos and T. S. Wang, "Managing the skin toxicities from new melanoma drugs," Current Treatment Options in Oncology, vol. 15, no. 2, pp. 281-301, 2014.

[38] Y. Zhao and A. A. Adjei, "The clinical development of MEK inhibitors," Nature Reviews Clinical Oncology, vol. 11, no. 7, pp. 385-400, 2014. 


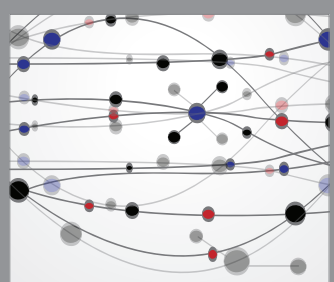

The Scientific World Journal
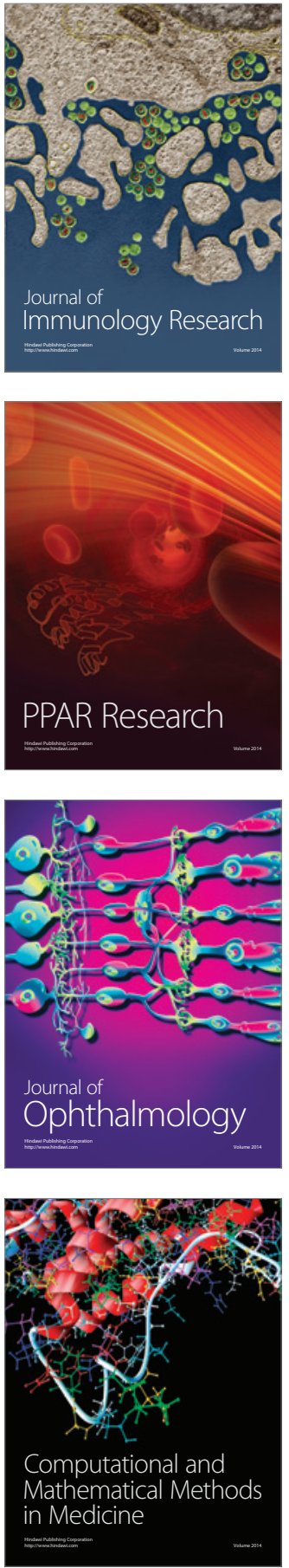

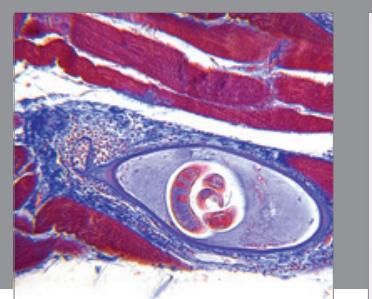

Gastroenterology Research and Practice

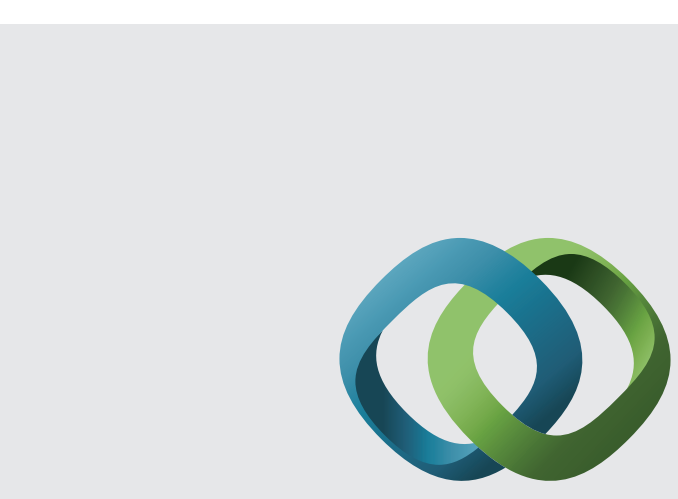

\section{Hindawi}

Submit your manuscripts at

http://www.hindawi.com
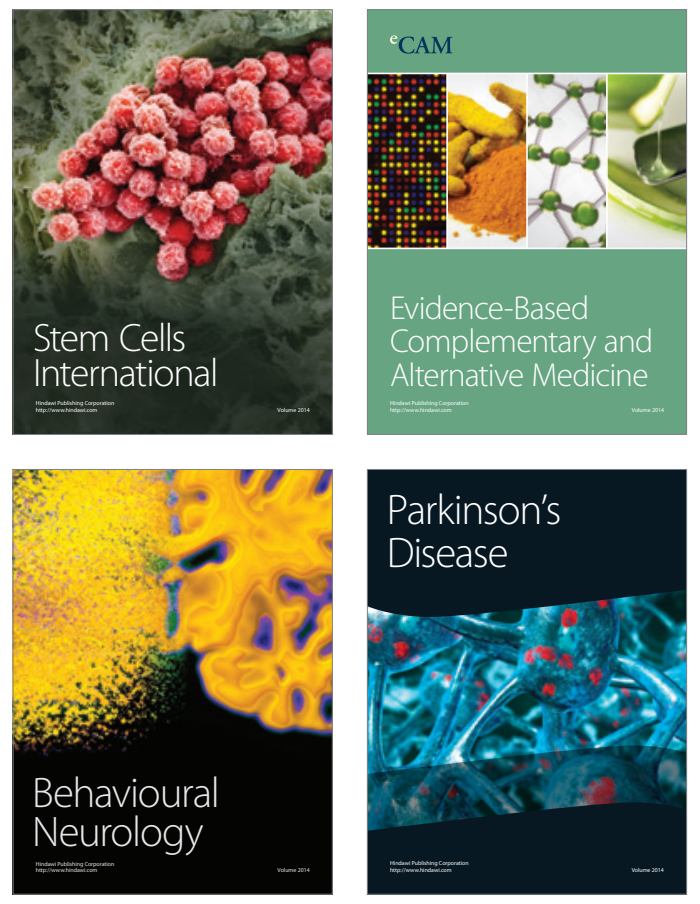
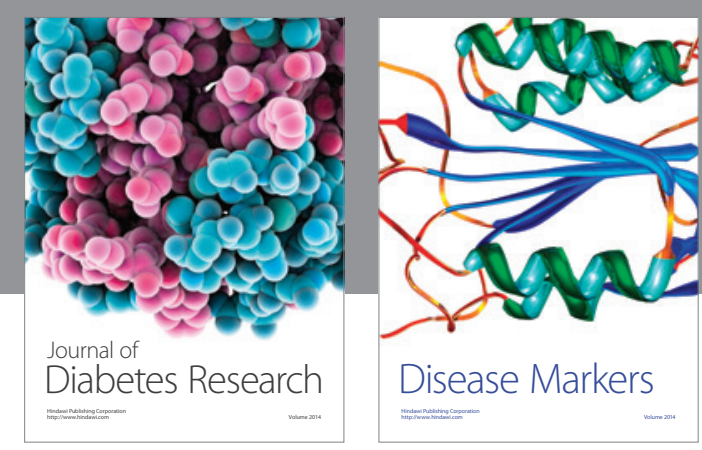

Disease Markers
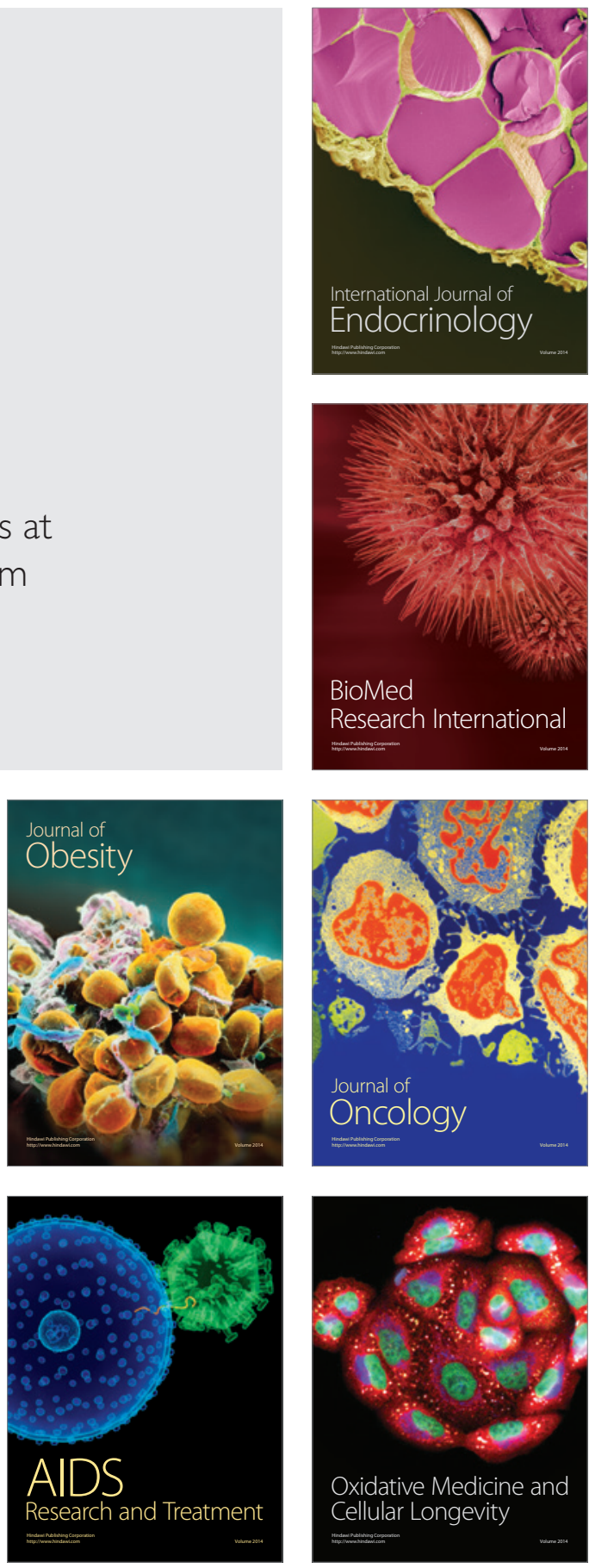